\title{
Giant aneurysms of coronary arteries accidentally discovered following out of hospital cardiac arrest
}

\author{
Olbrzymie tętniaki tętnic wieńcowych wykryte przypadkowo \\ u chorego z pozaszpitalnym zatrzymaniem krążenia
}

\section{Aleksander Trąbka-Zawicki, Krzysztof Żmudka}

Department of Haemodynamics and Angiocardiography, Institute of Cardiology, Jagiellonian University Medical College, John Paul II Hospital, Krakow, Poland

A 50-year-old male, a long-term smoker with a history of hypertension, and who had received renal transplantation 13 years earlier due to Alport syndrome, was brought to our centre by ambulance after an out of hospital cardiac arrest in the mechanism of ventricular fibrillation with a suspicion of non-ST-segment elevation acute myocardial infarction. On admission, the patient was in a critical state, unconscious, intubated, mechanically ventilated, haemodynamically stable with elevated blood pressure. Coronary angiography revealed multivessel disease with giant coronary aneurysms (Figs. 1, 2). The angioplasty of coronary arteries was deferred due to a complex angiographic picture, complete epicardial flow and stable haemodynamic course. Myocardial necrosis markers were insignificantly elevated. The patient was managed with induced therapeutic hypothermia according to European Society of Cardiology guidelines and cooled down to $33^{\circ} \mathrm{C}$, using an endovascular system (Cool-Gard). Echocardiographic examination showed normal left ventricular ejection fraction with left ventricular hypertrophy. During a stay in the intensive coronary care unit, we monitored the haemodynamic parameters using a pulmonary Swan-Ganz catheter. We found highly elevated cardiac output up to $11 \mathrm{~L} / \mathrm{min}$ and decreased systemic vascular resistance index (SVRI) $1,400 \mathrm{dyn} \times \mathrm{s} \times \mathrm{cm}^{-5} \times \mathrm{m}^{2}$. Therapeutic hypothermia (temperature of $33^{\circ} \mathrm{C}$ ) was applied for $12 \mathrm{~h}$, then the patient was gradually warmed to a temperature of $36.6^{\circ} \mathrm{C}$. Subsequent haemodynamic measurements revealed characteristics of hyperkinetic circulation (elevated cardiac output, maximally up to $16 \mathrm{~L} / \mathrm{min}$ with reduced SVRI of $870 \mathrm{dyn} \times \mathrm{s} \times \mathrm{cm}^{-5} \times \mathrm{m}^{2}$ ), most likely associated with active, large arteriovenous fistula for haemodialysis, which had not been used since the kidney transplant. On the third day of hospitalisation, after discontinuation of sedation, the patient was successfully extubated. Neurological examination did not reveal any focal damage in the central nervous system, which was confirmed by a computed tomography (CT) brain scan. Also an intracranial haemorrhage was excluded on CT. The Mini-Mental Status Examination showed a moderate degree of cognitive impairment with a score of 19/30 points on the Folstein test. This case of accidentally detected giant aneurysms of coronary arteries with multivessel disease was presented to the heart team in order to consider coronary artery bypass graft vs. medical management. The experts definitively recommended optimal medical therapy. After seven days of hospitalisation, the discharge pharmacotherapy included: acetylsalicylic acid, statin, calcium channel blocker, clonidine, immunosuppressive drugs, and a proton pump inhibitor. There was no recommendation regarding chronic applied anticoagulant drugs on discharge. Most aneurysms are associated with the presence of an atherosclerotic lesion, but the aetiology of genetic determinants in the course of Alport syndrome cannot be excluded.

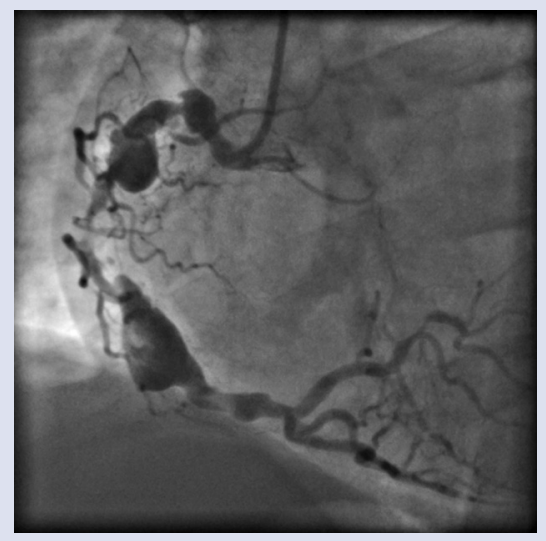

Figure 1. Coronary angiography in the LAO projection. Right coronary artery with significant atherosclerotic changes with scattered aneurysms

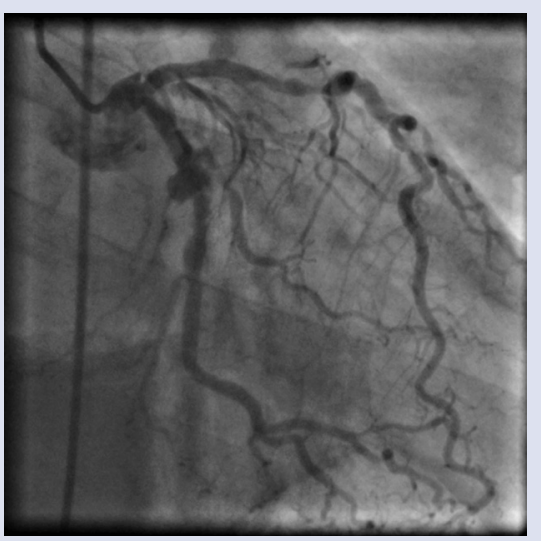

Figure 2. Coronary angiography in the CAUD RAO projection. Left coronary artery with significant atherosclerotic changes and aneurysms

\section{Address for correspondence:}

Dr. Aleksander Trąbka-Zawicki, Department of Haemodynamics and Angiocardiography, Institute of Cardiology, Jagiellonian University Medical College, John Paul II Hospital, ul. Prądnicka 80, 31-202 Kraków, Poland, e-mail: atz84@o2.pl

Conflict of interest: none declared 